\title{
Adhesion property of epoxidized natural rubber (ENR)-based adhesives containing calcium carbonate
}

\author{
B. T. Poh*, P. G. Lee, S. C. Chuah \\ School of Industrial Technology Universiti Sains Malaysia, 11800 Penang, Malaysia
}

Received 29 February 2008; accepted in revised form 10 April 2008

\begin{abstract}
The adhesion property (i.e. viscosity, loop tack and peel strength) of epoxidized natural rubber (ENR 25 and ENR 50 grade)-based pressure-sensitive adhesive was studied in the presence of calcium carbonate. The range of calcium carbonate loaded was from 10 to 50 parts per hundred parts of rubber (phr). Coumarone-indene resin was used as the tackifier and its concentration was fixed at $80 \mathrm{phr}$. Toluene was chosen as the solvent throughout the investigation. The substrates (PET film/paper) were coated with the adhesive using a SHEEN hand coater at a coating thickness of $60 \mu \mathrm{m}$. Viscosity of the adhesive was measured by a HAAKE Rotary Viscometer whereas loop tack and peel strength were determined by a Llyod Adhesion Tester operating at $30 \mathrm{~cm} / \mathrm{min}$. Results show that viscosity of ENR-based adhesives increases gradually with increase in calcium carbonate loading due to the concentration effect of the filler. However, for loop tack and peel strength, it passes through a maximum at $30 \mathrm{phr}$ calcium carbonate, an observation which is attributed to the optimum wettability of adhesive on the substrate at this adhesive composition. ENR 25-based adhesive consistently exhibits higher adhesion property than ENR 50 for all calcium carbonate loadings studied.
\end{abstract}

Keywords: adhesion, calcium carbonate, coatings, rubber

\section{Introduction}

Recently, we have carried out a systematic study of the viscosity, tack, peel and shear strength of natural rubber (SMR L, SMR 10 and SMR 20)-based pressure-sensitive adhesives [1-3]. The study shows that viscosity and tack of the adhesive increases with an increase in coumarone-indene resin loading. For the peel strength, it generally indicates an increasing trend with resin loading, an observation which is associated to the increasing wettability of adhesive on the substrate as tackifier is increased. However, shear strength decreases gradually with increasing resin content. Our recent study on the adhesion properties of SBR/SMR L-based adhesives indicates that the viscosity of adhesive decreases with increasing \% SBR whereas loop tack passes through a maximum value at $20 \%$
SBR composition [4]. Leong et al. [5] on the other hand have reported the viscoelastic properties of natural rubber pressure-sensitive adhesive using acrylic resin as a tackifier. Higher loss tangent at higher frequencies is obtained for good pressuresensitive adhesives. With respect to the adhesive prepared from epoxidized natural rubber, systematic investigation on its adhesion property is scarce. We have reported that peel strength of ENR-based adhesive passes through a maximum value at $40 \mathrm{phr}$ coumarone-indene resin [6]. Also, a gradual drop of shear strength with increasing tackifier loading is also observed. Recently, we have carried out a study on the effect of zinc oxide on the viscosity, tack and peel strength of ENR 25-based pressure-sensitive adhesives [7]. It is shown that viscosity and loop tack of adhesive increases with

*Corresponding author, e-mail: btpoh@usm.my

(C) BME-PT and GTE 
increasing zinc oxide concentration. However, peel strength passes through a maximum value at 30 $40 \mathrm{phr}$ of zinc oxide depending on the content of tackifier used. In order to understand better the dependence of adhesion property of adhesives on filler loading, we have extended a systematic investigation on the effect of calcium carbonate on the viscosity, tack and peel strength of pressure-sensitive adhesives prepared from two grades of ENR, i.e. ENR 25 and ENR 50.

\section{Experimental}

\subsection{Materials}

Two grades of epoxidized natural rubber, ENR 25 and ENR 50, having 25 and $50 \mathrm{~mol} \%$ of epoxidation respectively were used as the elastomers for the preparation of the pressure-sensitive adhesives. The rubbers were supplied by Rubber Research Institute of Malaysia (RRIM). Precipitated calcium carbonate with mean particle size of $10 \mu \mathrm{m}$ was used as the filler. It was not surface-treated. The tackifier used was coumarone-indene resin with an average molecular weight of 2000 and softening point of $80^{\circ} \mathrm{C}$. Toluene was used as the solvent throughout the study. These were commercial grade materials and used as supplied.

\subsection{Preparation of adhesive}

ENR 25 and ENR 50 were masticated on a two-roll mill for 10 minutes. $5 \mathrm{~g}$ of the masticated rubber was then dissolved in $20 \mathrm{ml}$ of toluene. The rubber solution was left overnight to ensure complete dissolution. $4 \mathrm{~g}$ of pulverized coumarone-indene resin corresponding to $80 \mathrm{phr}$ resin was added to the rubber solution with constant stirring. Then, five different weights of calcium carbonate powder, i.e., $0.5,1,1.5,2$ and $2.5 \mathrm{~g}$ corresponding to $10,20,30$, 40 and $50 \mathrm{phr}$ of filler were added separately to the rubber solution containing coumarone-indene resin. For comparison purposes, one control sample without calcium carbonate was used to prepare the adhesive.

\subsection{Measurement}

\subsubsection{Viscosity}

A HAAKE Rotary Viscometer (Model PK 100) was used to determine the viscosity of the adhe- sives. Spindle head $\left(\mathrm{PK} 1 ; 1^{\circ}\right)$ and the platform were wiped with acetone. The platform was then raised up to touch the spindle head. The gap between spindle head and platform was adjusted to zero before testing. A few drops of adhesive were put at the middle of platform which was then elevated to squeeze the adhesive. Excessive adhesive around the spindle head was wiped off with acetone. Testing was carried out for one minute or ten rounds of spinning at $30^{\circ} \mathrm{C}$. The average of five readings was taken as the average viscosity of the adhesive.

\subsubsection{Tack}

A polyethylene terephthalate (PET) substrate with dimension of $4 \mathrm{~cm} \times 25 \mathrm{~cm}$ was used to determine the loop tack of the adhesive. It was coated at the centre $(4 \mathrm{~cm} \times 4 \mathrm{~cm})$ by a SHEEN Hand Coater at a coating thickness of $60 \mu \mathrm{m}$. The coated PET was air dried at $30^{\circ} \mathrm{C}$ for 24 hours to eliminate the toluene in the adhesive. A loop was formed from the PET film and the outer surface with adhesive area was gently brought into contact with a glass plate. The debonding force from the glass plate was measured at $30^{\circ} \mathrm{C}$ by a Lloyd Adhesion Tester (Model LRXPlus with NEXYGEN software) operating at a testing rate of $30 \mathrm{~cm} / \mathrm{min}$. The three highest peaks from the test were used to compute the average debonding force. The loop tack was defined as the debonding force per area of contact with the glass plate $\left[\mathrm{N} / \mathrm{m}^{2}\right]$.

\subsubsection{Peel strength}

Polyethylene terephthalate (PET) film and release paper were used as the base stock and face stock respectively in the peel adhesion tests. In order to confirm the consistency of the results, three different modes of peel tests were conducted, viz. T-Peel Test, $90^{\circ}$ Peel Test and $180^{\circ}$ Peel Test. For the Tand $90^{\circ}$ Peel Tests, the dimensions of both substrates were $20 \mathrm{~cm} \times 4 \mathrm{~cm}$. However, for the $180^{\circ}$ Peel Test, the dimensions of PET film was $25 \mathrm{~cm} \times$ $4 \mathrm{~cm}$, whereas that of release paper was of $12 \mathrm{~cm} \times$ $6 \mathrm{~cm}$. For all peel tests, a SHEEN Hand Coater was used to coat the adhesive from the end of the PET film at a coating area and thickness of $10 \mathrm{~cm} \times 4 \mathrm{~cm}$ and $60 \mu \mathrm{m}$ respectively. The release paper was then placed on the coated PET film. The sample was air dried at $30^{\circ} \mathrm{C}$ for 24 hours to eliminate the toluene. The peel test was carried out at $30^{\circ} \mathrm{C}$ using a Lloyd 
Adhesion Tester operating at $30 \mathrm{~cm} / \mathrm{min}$. As in the tack test, the average peeling force was determined from the three highest peaks of the load-propagation graph. Peel strength is defined as the average load per width of the bondline required to separate progressively a flexible member from a rigid member or another flexible member (ASTM D 907).

\section{Results and discussion}

The effects of calcium carbonate on the viscosity, tack and peel strength of ENR 25 and ENR 50based pressure-sensitive adhesives are discussed below.

\subsection{Viscosity}

Figure 1 shows the dependence of viscosity of adhesive on calcium carbonate concentration. For both adhesives, viscosity increases gradually with increase in calcium carbonate loading. This observation is attributed to the thickening effect of calcium carbonate which acts as a filler in the adhesive formulation [8]. The higher the concentration of the filler, the greater is the thickening effect as reflected by the increase in viscosity. For all the loadings of filler, ENR 25 consistently indicates higher viscosity compared to that of ENR 50. The phenomenon may be explained by the stronger interaction (i.e. H-bonding) between ENR 25 and calcium carbonate filler. ENR 25 which has a lower $T_{g}$ (i.e. $-45^{\circ} \mathrm{C}$ ) interacts better with the filler due to its greater flexibility compared to ENR $50\left(T_{g}=\right.$ $\left.-20^{\circ} \mathrm{C}\right)$. The difference in viscosity between ENR 25 and ENR 50-based adhesives $\left(Z_{v}\right)$ with calcium carbonate loading is shown in Figure 2. $Z_{v}$ value increases rapidly from 0 to $10 \mathrm{phr}$ of filler loading and levels off after $10 \mathrm{phr}$ filler suggesting that the rate of increasing ENR 25-filler interaction

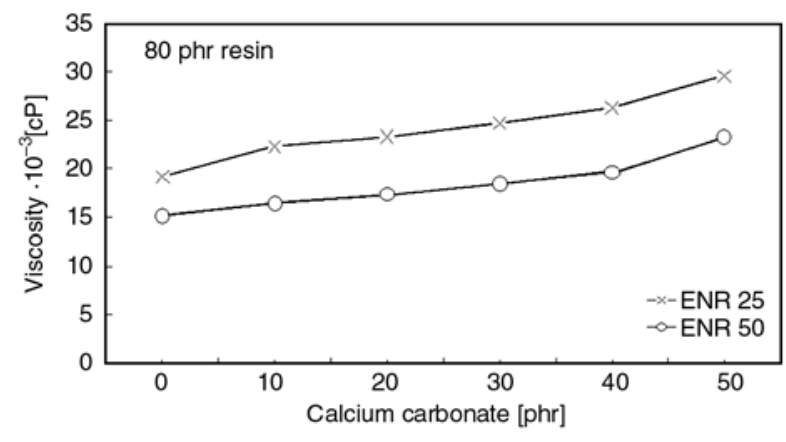

Figure 1. Variation of viscosity with calcium carbonate loading

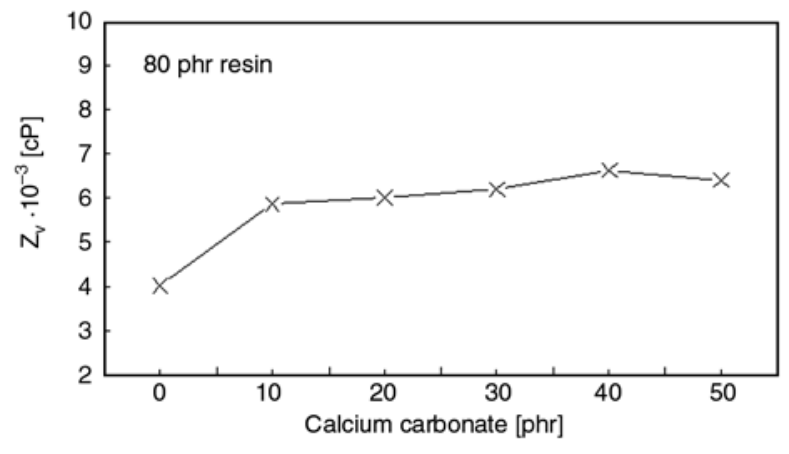

Figure 2. Variation of difference in viscosity $\left(Z_{v}\right)$ with calcium carbonate loading

is faster than that of ENR 25 at the initial loading of calcium carbonate. However, after $10 \mathrm{phr}$ of filler loading, rubber-filler interaction becomes nearly constant as shown by the plateau $Z_{v}$ value with further filler loading.

\subsection{Tack}

The dependence of loop tack on the calcium carbonate loading for ENR 25 and ENR 50 is shown in Figure 3. Tack may be defined as the property of a material which enables it to form a bond of measurable strength immediately upon contact with another surface, usually with low applied pressure [8]. It gives an indication of how quickly an adhesive can wet and make intimate contact with a surface of a substrate. Result indicates that loop tack passes through a maximum value at $30 \mathrm{phr}$ calcium carbonate loading for both rubbers studied. The increasing tack with increasing filler loading is attributed to the increasing wettability of adhesive on the substrate. At the maximum tack value, the adhesive conforms to the irregularities of the substrate, i.e. low surface energy condition is observed [9] at $30 \mathrm{phr}$ calcium carbonate content. Further increase in the filler content will cause a dilution

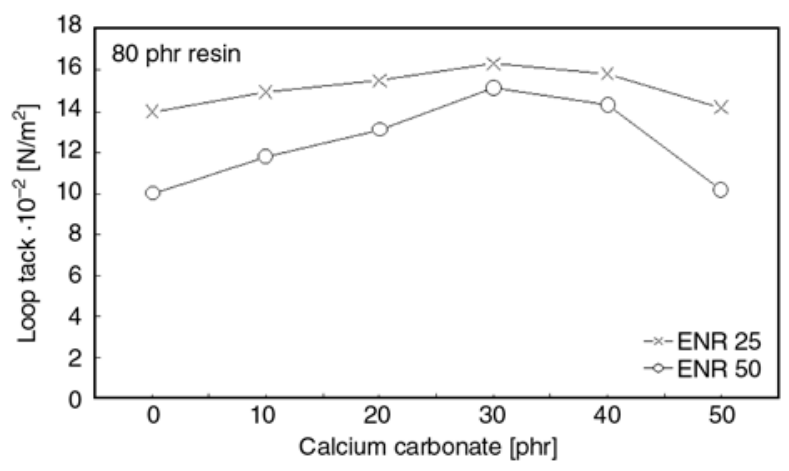

Figure 3. Variation of loop tack with calcium carbonate loading 


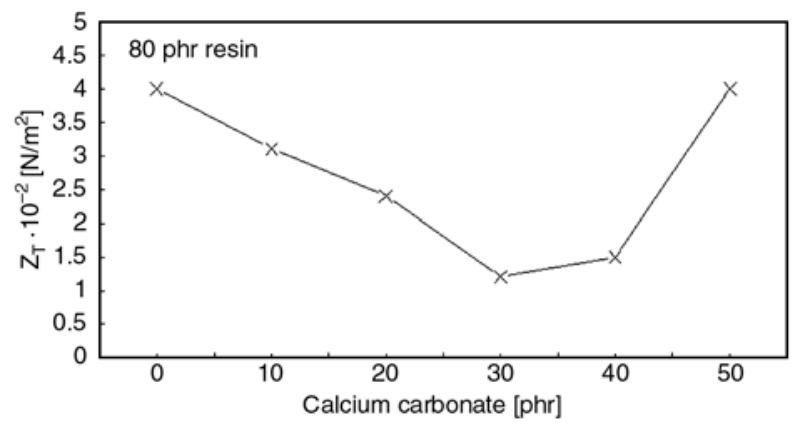

Figure 4. Variation of difference in loop tack $\left(Z_{T}\right)$ with calcium carbonate loading

effect which decreases the miscibility and wettability of adhesive as indicated by the lowering of tack after $30 \mathrm{phr}$ calcium carbonate loading. As in the case of viscosity, ENR 25-based adhesive consistently exhibits higher tack value compared to ENR 50 for all loadings of calcium carbonate. The difference in tack $\left(Z_{T}\right)$ between ENR 25 and ENR 50based adhesives is shown in Figure 4. $Z_{T}$ decreases with calcium carbonate loading until a minimum is reached at $30 \mathrm{phr}$ filler. After that it increases with further addition of the filler. This observation is attributed to the varying degree of interaction between ENR 25-calcium carbonate and ENR 50calcium carbonate which affects the tack property of the respective adhesives. At $30 \mathrm{phr}$ calcium carbonate loading, the difference in wettability between ENR 25 and ENR 50-based adhesive is minimal as reflected by the lowest $Z_{T}$ value. However, increasing filler content widens the respective tack values due to the greater drop of miscibility and wettability of ENR 50-based adhesive.

\subsection{Peel strength}

The effect of calcium carbonate on peel strength of ENR-based adhesive is shown in Figures 5-7 for

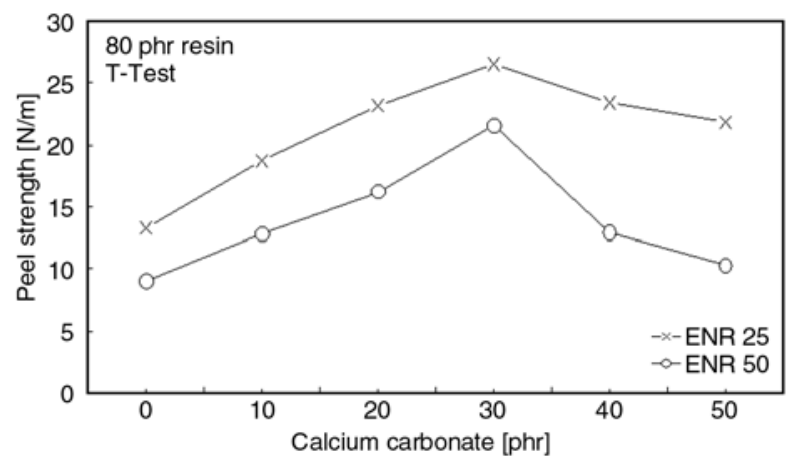

Figure 5. Peel strength (T-Test) versus calcium carbonate loading

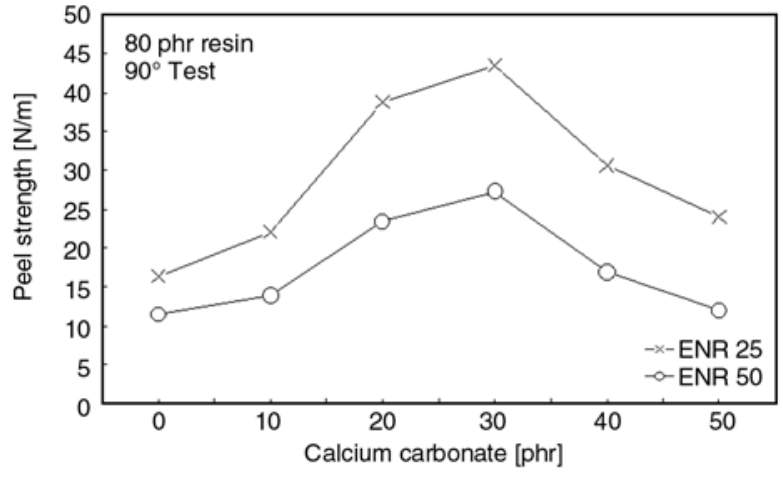

Figure 6. Peel strength $\left(90^{\circ}\right.$ Test) versus calcium carbonate loading

the T-, $90^{\circ}$ and $180^{\circ}$ Tests respectively at $80 \mathrm{phr}$ tackifier concentration. For all the three modes of testing, peel strength increases with increasing calcium carbonate loading up to $30 \mathrm{phr}$ filler content and drops with further filler loading. This phenomenon is due to the continuous lowering of surface tension by calcium carbonate and hence better wettability of adhesive on the substrate is observed. As in the case of tack, wettability reaches a maximum value at $30 \mathrm{phr}$ calcium carbonate loading for both rubbers studied. The increase in wettability enhances mechanical interlocking and anchorage of the adhesive in pores and irregularities in the adherent [10, 11]. After the optimum filler loading, peel strength decreases with further addition of filler because of the dilution effect of filler, thus reduces the miscibility and wettability of adhesive as exhibited by the drop in peel strength. From this study, ENR 25 consistently indicates higher peel strength than ENR 50, an observation which is similar to that reported in our earlier study of ENR in the absence of filler [6]. Figure 8 compares the peel strength of ENR 25 and ENR 50-based adhesives for various modes of peel tests. In all the tests, it is observed that ENR 25 gives higher peel strength than ENR

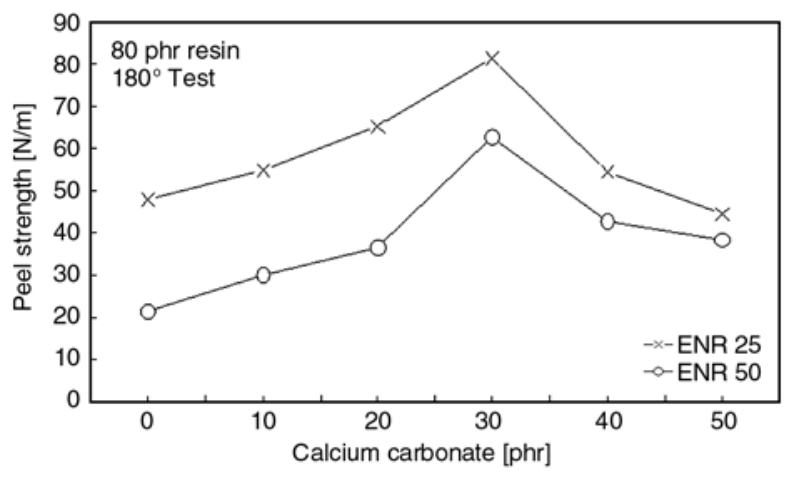

Figure 7. Peel strength $\left(180^{\circ}\right.$ Test $)$ versus calcium carbonate loading 


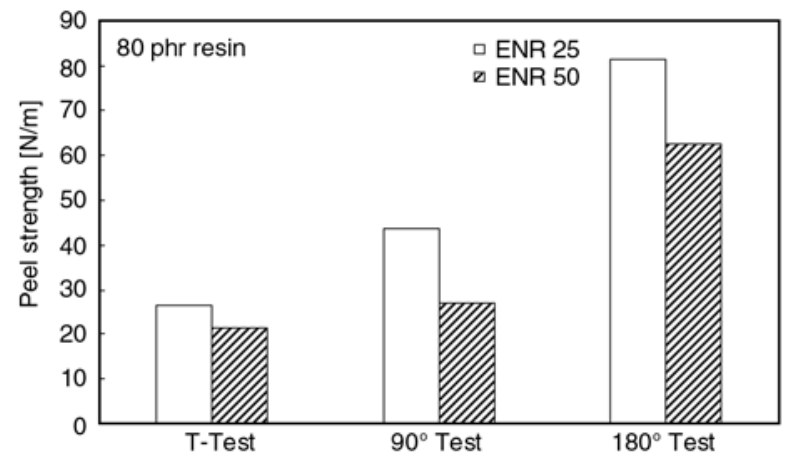

Figure 8. Comparison of peel strength between ENR 25 and ENR 50 at $30 \mathrm{phr}$ calcium carbonate

50. This observation is attributed to the greater flexibility of ENR 25 due to its lower $T_{g}$ value compared to ENR 50 as discussed earlier. This means that ENR 25-based adhesive will wet better than that of adhesive prepared from ENR 50. ENR 25 also undergoes more strain-induced crystallization [12-16] to enhance its resistance to rupture under an applied force so that the adhesive layer itself cannot easily be ruptured [8]. Figure 8 also shows that the peel strength obtained from the $180^{\circ}$ Peel Test is much higher than the other two modes of testing. This is due to the angle of testing, an observation which is consistent with our previous report on the study of peel strength of SMR 10-based pressure-sensitive adhesive [1]. A higher peel force is needed in the $180^{\circ}$ peel test which means that the rubber chains will undergo more strain-induced crystallization than the other two peel tests and hence, a higher peel strength is obtained. In all cases, the failure mode is essentially adhesive in nature.

\section{Conclusions}

The following conclusions can be drawn from this study:

1. Viscosity of ENR-based adhesives increases gradually with increase in calcium carbonate loading, an observation which is attributed to the thickening effect of calcium carbonate which acts as a filler in the adhesive system. ENR 25 consistently shows higher viscosity compared to that of ENR 50 indicating that interaction between ENR 25 and calcium carbonate is stronger compared to ENR 50.

2. Loop tack passes through a maximum value at $30 \mathrm{phr}$ calcium carbonate loading for both rub- bers studied. This observation is associated with the increasing wettability with increasing filler loading. However, further increase in the filler loading will decrease the miscibility and wettability of adhesive due to the dilution effect of the filler.

3. Peel strength increases with increasing calcium carbonate loading up to $30 \mathrm{phr}$ filler content and drops with further filler loading, a phenomenon similar to that of tack test, i.e. varying degree of miscibility and wettability of adhesive with filler loading is observed. The increase in wettability enhances mechanical interlocking and anchorage of the adhesive in pores and irregularities in the substrate. ENR 25-based adhesive shows higher peel strength than that of ENR 50, an observation which is attributed to the greater flexibility of ENR 25 compared to ENR 50 due to the lower $T_{g}$ in the former.

\section{Acknowledgements}

The authors acknowledge the research grant (FRGS) provided by Universiti Sains Malaysia that has resulted in this article.

\section{References}

[1] Poh B. T., Chang Y. Y.: Viscosity and peel strength of SMR 10-based pressure-sensitive adhesives. PolymerPlastics Technology and Engineering, 45, 1251-1256 (2006)

[2] Poh B. T., Chee C. L.: Effect of coumarone-indene resin on adhesion property of SMR 20-based pressuresensitive adhesives. International Journal of Polymeric Materials, 56, 247-255 (2007).

[3] Poh B. T., Kwo H. K.: Shear strength of SMR-based pressure-sensitive adhesives. Polymer-Plastics Technology and Engineering, 46, 1021-1024 (2007).

[4] Poh B. T., Ong L. N.: Adhesion properties of styrenebutadiene rubber (SBR)/Standard Malaysian Rubber (SMR L)-based adhesives in the presence of phenol formaldehyde resin. Express Polymer Letters, 1, 654659 (2007).

[5] Leong Y. C., Lee L. M. S., Gan S. N.: The viscoelastic properties of natural rubber pressure-sensitive adhesive using acrylic resin as a tackifier. Journal of Applied Polymer Science, 88, 2118-2123 (2003).

[6] Poh B. T., Kwo H. K.: Peel and shear strength of pressure-sensitive adhesives prepared from epoxidized natural rubber. Journal of Applied Polymer Science, 105, 680-684 (2007). 
[7] Poh B. T., Chow S. K.: Effect of zinc oxide on the viscosity, tack and peel strength of ENR 25-based pressure-sensitive adhesives. Journal of Applied Polymer Science, 106, 333-337 (2007).

[8] Skeist I.: Handbook of adhesives. Van Nostrand Reinhold, New York (1990).

[9] Satas D.: Handbook of pressure-sensitive adhesive technology. Van Nostrand Reinhold, New York (1982).

[10] Gierenz G., Karmann W.: Adhesives and adhesive tapes. Wiley-VCH, New York (2001).

[11] Lee L. H.: Adhesive bonding. Plenum Press, New York (1991).

[12] Poh B. T., Khok G. K.: Tensile property of epoxidized natural rubber/natural rubber blends. Polymer-Plastics Technology and Engineering, 39, 151-161 (2000).
[13] Davies C. K. L., Wolfe S. V., Gelling I. R., Thomas A. G.: Strain crystallization in random copolymers produced by epoxidation of cis 1.4 polyisoprene. Polymer, 24, 107-113 (1983).

[14] Sadequl A. M., Poh B. T., Ishiaku U. S.: Effect of filler loading on the mechanical properties of epoxidized natural rubber (ENR 25) compared with natural rubber (SMR L). International Journal of Polymeric Materials, 43, 261-278 (1999).

[15] Poh B. T., Ismail H., Quah E. H., Chin P. L.: Cure and mechanical properties of filled SMR L/ENR 25 and SMR L/SBR blends. Journal of Applied Polymer Science, 81, 47-52 (2001).

[16] Poh B. T., Ismail H., Quah E. H.: Fatigue, resilience and hardness properties of unfilled SMR L/ENR 25 and SMR L/SBR blends. Polymer Testing, 20, 389 394 (2001). 